\title{
An analysis of functional outcome following tendon augmentation surgeries in patients presenting with steroid-induced tendo achilles rupture and spontaneous tendo achilles ruptures
}

\author{
Nagakiran K.V ${ }^{1, *}$, Prasad Soraganvi², Uma M.A ${ }^{3}$, Sudeep M.N ${ }^{4}$, Bharadwaj MSC ${ }^{5}$ \\ ${ }^{1,4}$ Assistant Professor, ${ }^{2,3}$ Associate Professor, ${ }^{5}$ Resident, Dept. of Orthopaedics, PES Institute of Medical Sciences and Research, \\ Kuppam, Andhra Pradesh, India
}

*Corresponding Author: Nagakiran K.V

Email: drnagakiran@gmail.com

\begin{abstract}
Introduction: Achilles tendon is the strongest tendon in the body, paradoxically is also the commonest one to undergo rupture. Corticosteroids are one of the most commonly used drugs in tendon disorders; also it is blamed for early and late ruptures. We wanted to assess whether there is any difference in functional outcome in steroid-induced TA rupture group versus spontaneous (no steroid injection) TA rupture.

Materials and Methods: A total of 12 patients were included in the study as per inclusion-exclusion criteria and preoperatively grouped based on previous history of intralesional steroid injection. Both the group underwent same tendon augmentation surgeries and similar physiotherapy protocols. Functional outcome was assessed using AOFAS and Leppilahti Scores.

Results: Better functional outcome was seen in the group with no previous exposure of intralesional steroid injection which was statistically significant $(\mathrm{p}<0.05)$ which was confirmed in both scoring systems.

Conclusion: Uses of intralesional steroid correlates negatively with outcome.
\end{abstract}

Keywords: Achilles tendon disorders, Tendo Achilles ruptures, Peroneus Brevis, Intralesional steroid injection, Tendon augmentation surgeries.

\section{Introduction}

Achilles tendon is the strongest tendon in the body, paradoxically is also the commonest one to undergo rupture. ${ }^{1}$ Disorders of Tendo Achilles (TA) are quite common in sporting as well as in general population.

Repetitive micro trauma and decreased tendon vascularity associated with increasing age have been definitely shown to correlate to Achilles tendon disorders. ${ }^{2}$ Several mechanical factors like improper footwear with rigid soles, and running on irregular grounds play an important role in causing TA ruptures. ${ }^{2}$

Management options for TA tendinosis include rest, ice therapy, non-steroidal anti-inflammatory medications, physiotherapy and footwear modifications with custom insoles. ${ }^{2}$ Eccentric loading exercises have been proven to be effective to the tune of $60-90 \%$. $^{3-5}$

Fredberg et al. found good improvement after peritendinous injection of corticosteroid only in short term. ${ }^{6,7}$ Oral as well as intralesional usage of steroid has been associated with increased incidence of TA ruptures. Corticosteroids are one of the most commonly used drugs in tendon disorders. ${ }^{8}$ Often misused; the potential risks of adverse effects outweigh benefits. Histological studies in tendinopathy have shown the presence of degeneration and absence of inflammatory markers. ${ }^{9}$ Hence the role of steroids as an antiinflammatory agent in tendinopathies is doubtful and debatable. Overall incidence of complications after corticosteroid injection is difficult to measure because of its widespread use and its complications are not commonly reported. Spontaneous complete ruptures have also been reported after steroid injections. ${ }^{10,11}$
There is paucity of literature detailing long-term effects of Corticosteroid injections in TA tendinopathies. We wanted to assess whether there is any association in patients presenting concerning Steroid induced TA ruptures as against spontaneous TA ruptures(patients have not received intralesional steroid injections).

With this background, we conducted a study in our hospital to assess the functional outcome after surgical treatment for TA rupture. We wanted to evaluate whether there is any difference in functional outcome in steroid-induced TA rupture group versus spontaneous (no steroid injection) TA rupture.

\section{Materials and Methods}

This study was a prospective, intention to treat study done at PES Institute of medical sciences and research, Kuppam during March 2015 to Sept 2017. The study subjects included patients who presented with TA ruptures. Patients were allocated into two groups. Group A (Steroid group) included all patients who had received at least one intralesional steroid injection in the past one year prior to rupture of Achilles tendon. Group B included all other patients who had presented with tendo Achilles ruptures without previous history of local steroid injections. Selection of patients was based on inclusion and exclusion criteria as given below.

\section{Inclusion Criteria}

1. All patients aged above 18yrs with insertional tendinosis and TA ruptures 


\section{Exclusion Criterion}

1. Age less than 18yrs with TA ruptures

2. Peripheral vascular disease

3. Patients refusing to be a part of the study

4. Patients with TA ruptures associated with neurovascular injuries

5. Patients with TA ruptures and Fractures of ipsilateral lower limb

The American Orthopaedic Foot and Ankle Society (AOFAS) Ankle-Hindfoot scale and The Leppihilati Scores were employed for outcome assessment following Tendon augmentation surgeries.

The AOFAS Ankle-Hindfoot scale developed in 1994 is universally accepted outcome measure for comparing different conditions of hind foot ${ }^{12}$ (Table 1). This is a clinician-based outcome scale collects both subjective and objective factors into numerical scales and has a maximum total Score of 100 points. The subjective portion has been shown to have satisfactory reliability and responsiveness. ${ }^{13,14}$

The Leppilahti Score, described in 1998 by Leppilahti et al (Table 2) is a specific evaluation tool for assessing outcome after Achilles tendon ruptures. ${ }^{15}$ This scoring system combines both subjective assessments of symptoms and objective measures, such as ankle range of motion (ROM) and isokinetic calf strength. It has a total of seven items giving a sum of 100 points as the best possible score.

A detailed history was taken and clinical examination performed for all the subjects included in the study. Preoperative AOFAS Ankle-Hindfoot scale and The Leppihilati scores were tabulated. After appropriate lab investigations and preanesthetic evaluation, patients underwent surgery under spinal anesthesia and tourniquet control. Postero lateral skin incision was used. Ruptured ends of TA were freshened, intratendinous calcification was excised. Peroneus Brevis tendon was used for tendon augmentation. Interferential screw fixation technique was employed for securing the tendons after drilling a tunnel in calcaneum (Fig. 1-8). Layered tension free suturing was done. Operated Limb was immobilized in plaster slab in resting equines position. Suture removal was done at 2 weeks and later limb was immobilized in plaster cast in plantigrade position. At 6 weeks passive range of motion (ROM) exercises were initiated (Fig. 11-12). Graduated weight-bearing was allowed on the operated limb from 12 weeks onwards (Fig. 13).

Patients were assessed before surgery and during follow-up at six weeks, $3^{\text {rd }}$ month and at $6^{\text {th }}$ month using AOFAS Ankle-Hindfoot scale and The Leppihilati Scores. Standard physical rehabilitation was given to all patients in the post operative period.

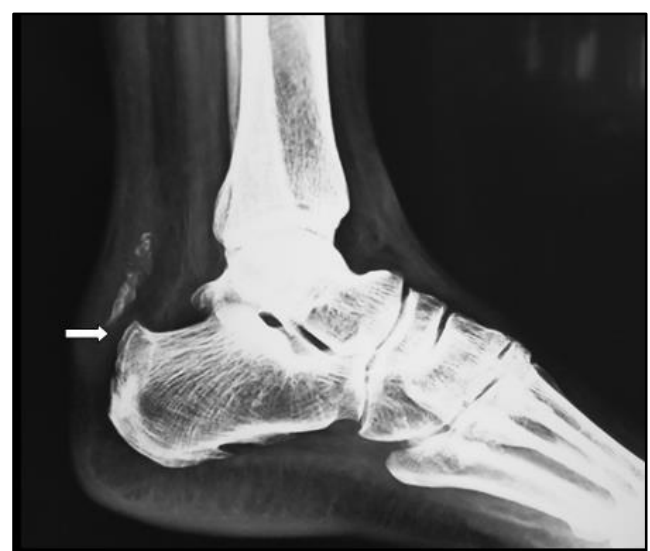

Fig. 1: Pre-op X-ray showing calcific tendinosis with rupture indicated by arrow

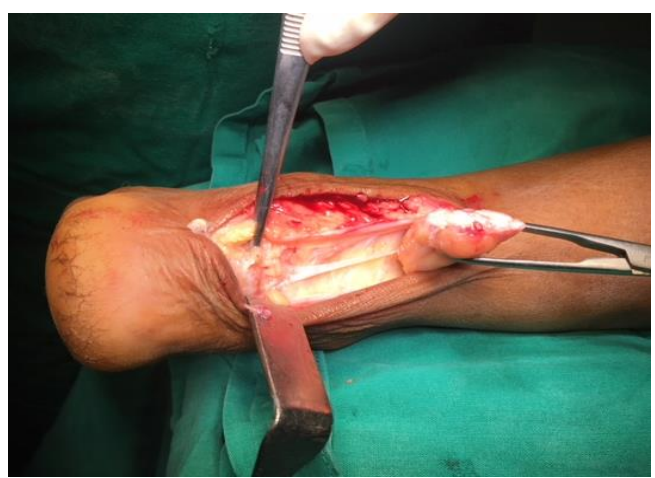

Fig 2: Complete rupture of TA with calcification

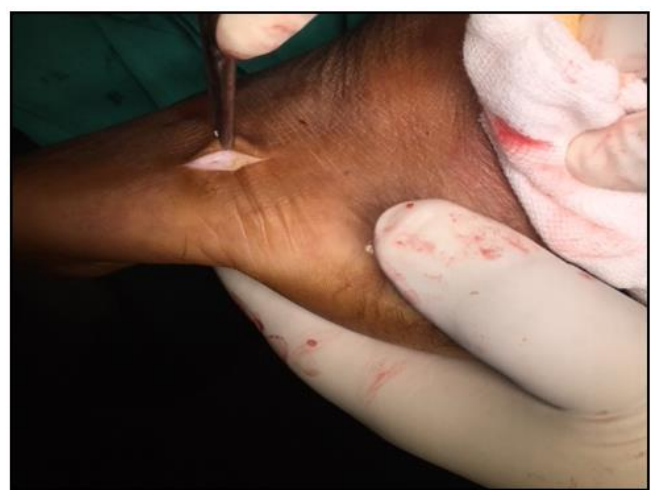

Fig. 3: Incision for peroneus brevis

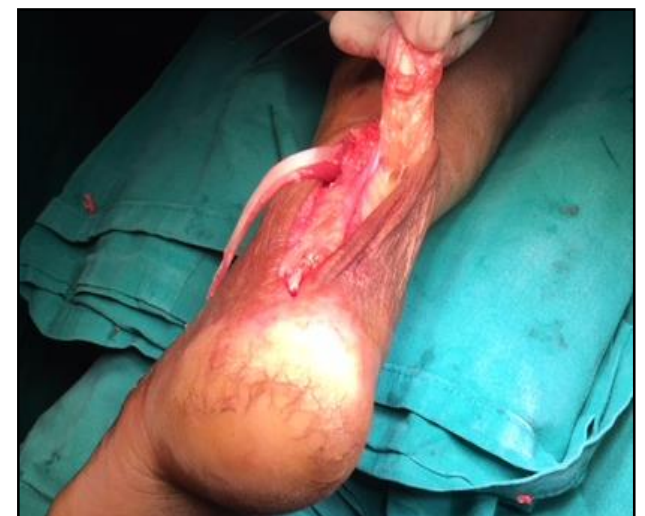

Fig. 4: Harvesting of peroneus brevis 


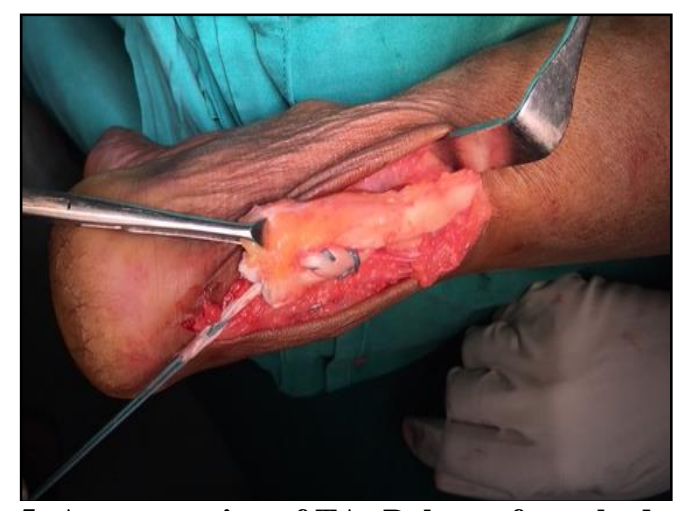

Fig. 5: Augmentation of TA; Pulvertaft method

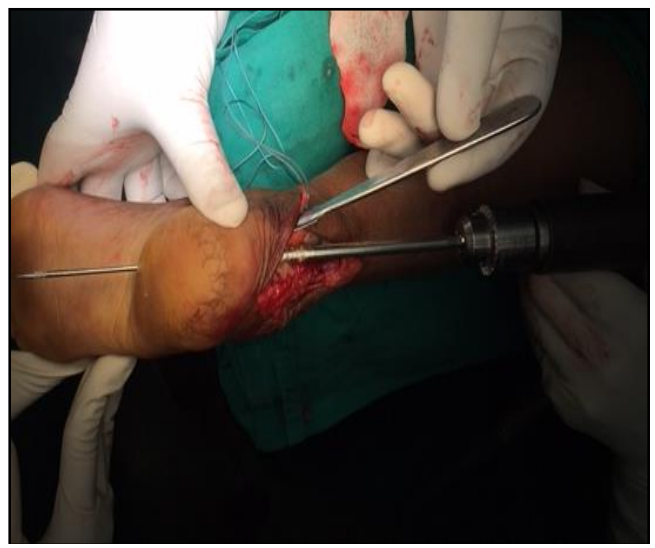

Fig. 6. Osseous tunnel in calcaneum

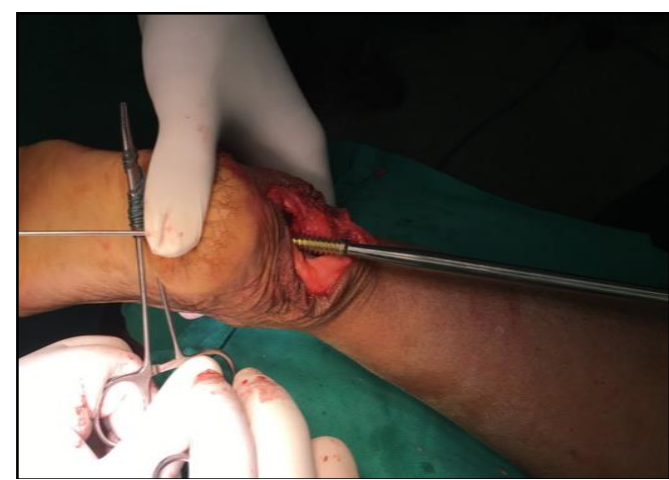

Fig. 7: Anchoring of peroneus brevis with interference screw

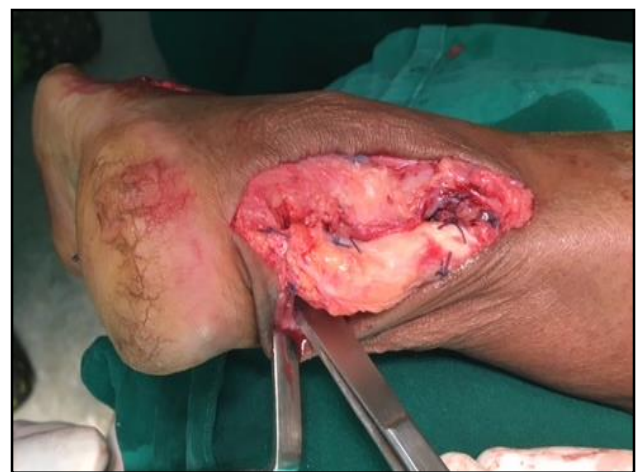

Fig. 8: Final repair of paratenon

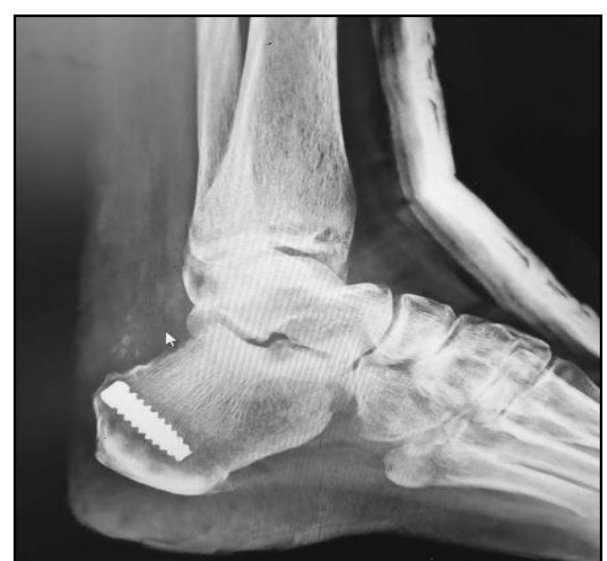

Fig. 9: Post operative x-ray

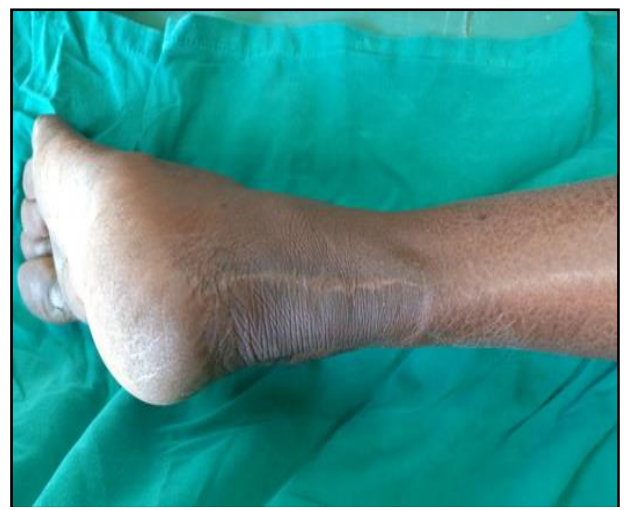

Fig. 10: Post operative scar at 6weeks follow-up

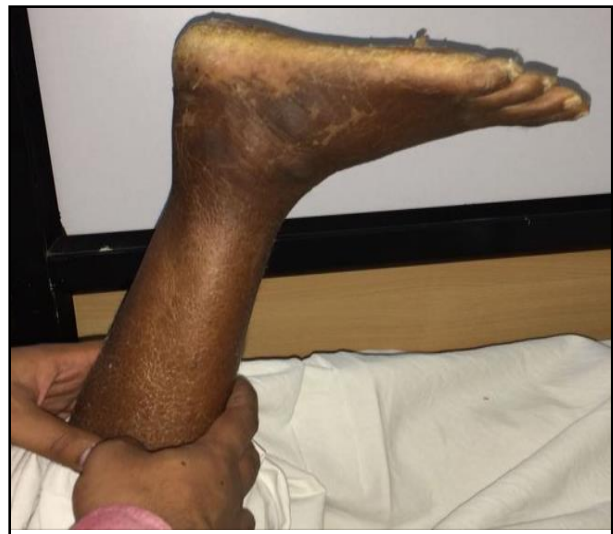

Fig. 11: Thompson test-part 1- before squeezing calf muscle 


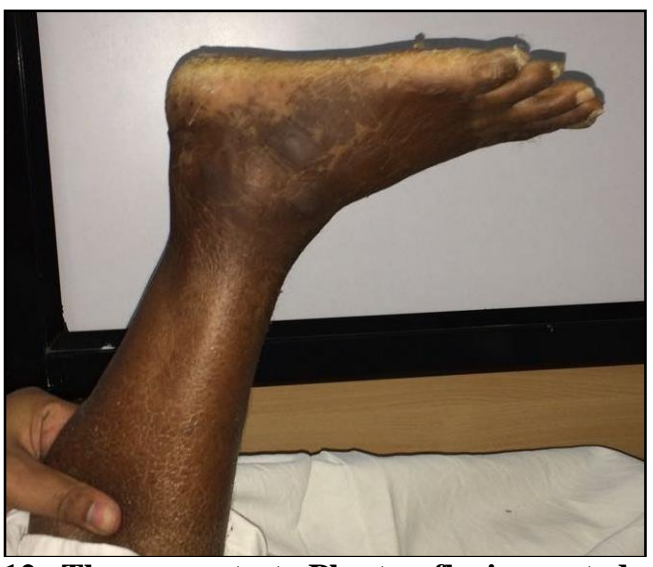

Fig. 12: Thompson test- Plantar flexion noted after squeezing calf muscle confirming integrity of gastroc-soleus complex.

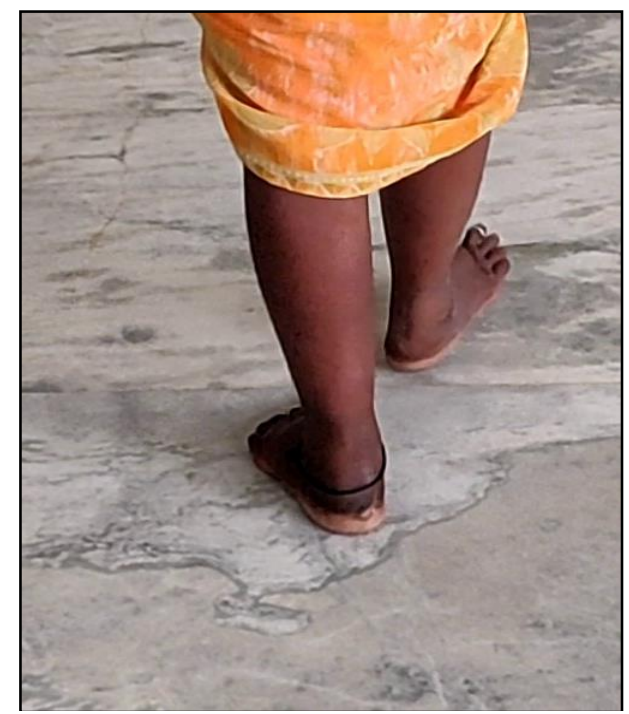

Fig. 13: Patient bearing weight on operated limb

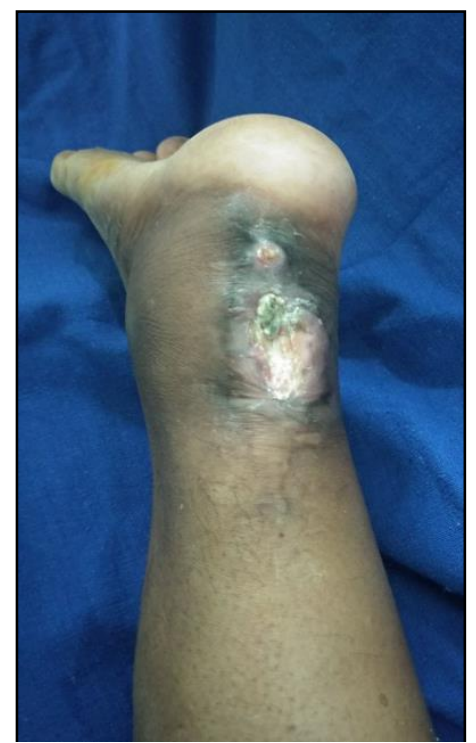

Fig. 14: Delayed wound healing noticed in Patient 6settled with conservative management

\section{Statistical Analysis}

Comparison was done between Group A (Steroid group) and Group B (spontaneous rupture- no steroid injection) using data obtained from AOFAS AnkleHindfoot scale and The Leppihilati Score. Statistical analysis was done by using SPSS 20 software. Independent t-test was used to compare the mean difference between two groups. Tests for statistical significance were assessed.

\section{Results}

During study period, a total of 15 patients with TA rupture were admitted. Only 12 patients were included in the study after applying inclusion and exclusion criteria. 6 patients presented with previous history of local steroid injections in the last one year. One patient had received 2 local steroid injections. All patients were available for follow up for a minimum period of 9 months. Average age at presentation was 58.16 years and 51yrs respectively in Group A and Group B. Both the groups had equal male and female patients. 2 Patients in Group A had well-controlled type II diabetes mellitus. One patient had wound healing problem in Group A (Fig. 14) which settled with regular dressings. There was no re-ruptures of the augmented TA in both the groups. One patient in Group A had sensory problem. (Table 5)

Average Pre operative AOFAS Ankle-Hindfoot scale was 35.50 and 41.17 respectively in Group A and Group B. In Group A Ankle-Hindfoot score improved to $46.83,75.67$ and 81.00 at 6 weeks, $3^{\text {rd }}$ month and $6^{\text {th }}$ months respectively. In Group B the scores were 50.67, 82.00 and 90.17 at similar $6^{\text {th }}$ week, $3^{\text {rd }}$ month and $6^{\text {th }}$ month. Although improvement in scores in group B was noted at $6^{\text {th }}$ week and $3^{\text {rd }}$ month, the difference was not statistically significant. At $6^{\text {th }}$ month follow up however the mean differences in group A and Group B was statistically significant (p-value-0.009) implying better functional outcome in Group B.

The Mean pre operative Leppihilati Score was 24.17 and 21.67 in Group A and B respectively. The mean difference at six weeks and $3^{\text {rd }}$ month between scores between Group A and Group B were not statistically significant (p-value 0.45 and 0.64 respectively). At $6^{\text {th }}$ month however, the mean difference was statistically significant (p-value $0.01<0.05)$. 
Table 1: The AOFAS Ankle - hindfoot scale

\begin{tabular}{|c|c|}
\hline \multicolumn{2}{|l|}{ Pain (40 points) } \\
\hline None & 40 \\
\hline Mild, occasional & 30 \\
\hline Moderate, daily & 20 \\
\hline Severe, almost always present & 0 \\
\hline \multicolumn{2}{|l|}{ Function (50 points) } \\
\hline \multicolumn{2}{|l|}{ Activity limitations, support requirement } \\
\hline No limitations, no support & 10 \\
\hline No limitation of daily activities, limitation of recreational activities, no support & 7 \\
\hline Limited daily and recreational activities, cane & 4 \\
\hline Severe limitation of daily and recreational activities, walker, crutches, wheelchair, brace & 0 \\
\hline \multicolumn{2}{|l|}{ Maximum walking distance, blocks } \\
\hline Greater than 6 & 5 \\
\hline $4-6$ & 4 \\
\hline $1-3$ & 2 \\
\hline Less than 1 & 0 \\
\hline \multicolumn{2}{|l|}{ Walking surfaces } \\
\hline No difficulty on any surface & 5 \\
\hline Some difficulty on uneven terrain, stairs, inclines, ladders & 3 \\
\hline Severe difficulty on uneven terrain, stairs, inclines, ladders & 0 \\
\hline \multicolumn{2}{|l|}{ Gait abnormality } \\
\hline None, slight & 8 \\
\hline Obvious & 4 \\
\hline Marked & 0 \\
\hline \multicolumn{2}{|l|}{ Sagittal motion (flexion plus extension) } \\
\hline Normal or mild restriction $\left(30^{\circ}\right.$ or more $)$ & 8 \\
\hline Moderate restriction $\left(15^{\circ}-29^{\circ}\right)$ & 4 \\
\hline Severe restriction (less than 150) & 0 \\
\hline \multicolumn{2}{|l|}{ Hindfoot motion (inversion plus eversion) } \\
\hline Normal or mild restriction $(75 \%-100 \%$ normal $)$ & 6 \\
\hline Moderate restriction $(25 \%-74 \%$ normal) & 3 \\
\hline Marked restriction (less than $25 \%$ normal) & 0 \\
\hline \multicolumn{2}{|l|}{ Ankle-hindfoot stability (anteroposterior, varus-valgus) } \\
\hline Stable & 8 \\
\hline Definitely unstable & 0 \\
\hline \multicolumn{2}{|l|}{ Alignment (10 points) } \\
\hline Good, plantigrade foot, midfoot well aligned & 10 \\
\hline Fair, plantigrade foot, some degree of midfoot malalignment observed, no symptoms & 5 \\
\hline Poor, nonplantigrade foot, severe malalignment, symptoms & 0 \\
\hline
\end{tabular}

Table 2: The leppilahti score

\begin{tabular}{|l|c|}
\hline \multicolumn{1}{|c|}{ Pain } \\
\hline None & 15 \\
\hline Mild, no limitations on recreational activities & 10 \\
\hline Moderate, limitations on recreational, but not daily activities & 5 \\
\hline Severe, limitations on recreational and daily activities & 0 \\
\hline Stiffness & 15 \\
\hline None & 10 \\
\hline Mild, occasional, no limitations on recreational activities & 5 \\
\hline Moderate, limitations on recreational, but not daily activities & 0 \\
\hline Severe, limitations on recreational and daily activities & 15 \\
\hline Calf muscle weakness (subjective) & 10 \\
\hline None & 5 \\
\hline Mild, no limitations on recreational activities & \\
\hline Moderate, limitations on recreational, but not daily activities &
\end{tabular}




\begin{tabular}{|l|c|}
\hline Severe, limitations on recreational and daily activities & 0 \\
\hline Footwear restrictions & 10 \\
\hline None & 5 \\
\hline Mild, most shoes tolerated & 0 \\
\hline Moderate, unable to tolerate fashionable shoes, modified shoes tolerated & 15 \\
\hline Active range of motion (ROM) difference between ankles & 0 \\
\hline Normal $\left(<6^{\circ}\right)$ & 5 \\
\hline Mild $\left(6^{\circ}-10^{\circ}\right)$ & 0 \\
\hline Moderate $\left(11^{\circ}-15^{\circ}\right)$ & \\
\hline Severe $\left(>15^{\circ}\right)$ & 15 \\
\hline Subjective result & 10 \\
\hline Very satisfied & 5 \\
\hline Satisfied with minor reservations & 0 \\
\hline Satisfied with major reservations & \\
\hline dissatisfied & 15 \\
\hline Isokinetic muscle strength (score) & 10 \\
\hline Excellent & 5 \\
\hline Good & 0 \\
\hline Fair & \\
\hline Poor & \\
\hline
\end{tabular}

Table 3: Group statistics- functional outcome with respect to previous steroid injections

\begin{tabular}{|c|c|c|c|c|c|}
\hline & $\begin{array}{c}\text { Previous Steroid } \\
\text { injections }\end{array}$ & $\begin{array}{c}\text { Total } \\
\text { Number }(\mathbf{N}) \\
\end{array}$ & Mean & $\begin{array}{l}\text { Standard } \\
\text { Deviation }\end{array}$ & Significance \\
\hline \multirow{2}{*}{ Preoperative AOFAS score } & Group A (yes) & 6 & 35.50 & 9.894 & \multirow{2}{*}{0.34} \\
\hline & Group B (no) & 6 & 41.17 & 10.722 & \\
\hline \multirow{2}{*}{ Preoperative leppilahti score } & Group A (yes) & 6 & 24.17 & 10.685 & \multirow{2}{*}{0.68} \\
\hline & Group B (no) & 6 & 21.67 & 9.832 & \\
\hline \multirow{2}{*}{$\begin{array}{l}6 \text { week postoperative AOFAS } \\
\text { score }\end{array}$} & Group A (yes) & 6 & 46.83 & 8.232 & \multirow{2}{*}{0.38} \\
\hline & Group B (no) & 6 & 50.67 & 6.314 & \\
\hline \multirow{2}{*}{$\begin{array}{l}6 \text { week postoperative leppilahti } \\
\text { score }\end{array}$} & Group A (yes) & 6 & 31.67 & 10.801 & \multirow{2}{*}{0.45} \\
\hline & Group B (no) & 6 & 35.83 & 7.360 & \\
\hline \multirow{2}{*}{$\begin{array}{l}3 \text { month postoperative AOFAS } \\
\text { score }\end{array}$} & Group A (yes) & 6 & 75.67 & 5.989 & \multirow{2}{*}{0.11} \\
\hline & Group B (no) & 6 & 82.00 & 6.512 & \\
\hline \multirow{2}{*}{$\begin{array}{l}3 \text { months postoperative leppilahti } \\
\text { score }\end{array}$} & Group A (yes) & 6 & 77.50 & 7.360 & \multirow{2}{*}{0.64} \\
\hline & Group B (no) & 6 & 79.17 & 3.764 & \\
\hline \multirow{2}{*}{$\begin{array}{l}6 \text { months postoperative AOFAS } \\
\text { score }\end{array}$} & Group A (yes) & 6 & 81.00 & 5.177 & \multirow{2}{*}{0.009} \\
\hline & Group B (no) & 6 & 90.17 & 4.579 & \\
\hline \multirow{2}{*}{$\begin{array}{l}6 \text { Months postoperative } \\
\text { leppilahti score }\end{array}$} & Group A (yes) & 6 & 85.83 & 3.764 & \multirow{2}{*}{0.01} \\
\hline & Group B (no) & 6 & 91.67 & 2.582 & \\
\hline
\end{tabular}

Table 4: Functional outcome with different scoring systems

\begin{tabular}{|l|c|c|c|c|}
\hline & \multicolumn{2}{|c|}{ Group A(Steroid group) $(\mathbf{n = 6})$} & Group B (N=6) & \\
\hline & AOFAS Scale & Leppilahti Score & AOFAS Scale & Leppilahti Score \\
\hline Excellent results $(>85)$ & $33 \%(\mathrm{n}=2)$ & 5 & $100 \%(\mathrm{n}=6)$ & 6 \\
\hline Good $(70-85)$ & $67 \%(\mathrm{n}=4)$ & 1 & nil & nil \\
\hline Fair $(50-75)$ & nil & nil & nil & nil \\
\hline poor $(<50)$ & nil & nil & nil & nil \\
\hline
\end{tabular}

Table 5: Complications

\begin{tabular}{|l|c|c|}
\hline \multicolumn{1}{|c|}{ Complications } & Group A(Steroid group) $(\mathbf{n = 6})$ & Group B (N=6) \\
\hline Wound healing problems & 1 & 0 \\
\hline Infections & 0 & 0 \\
\hline Rerupture & 0 & 0 \\
\hline
\end{tabular}




\section{Discussion}

It was a beginning of a new era when the discovery of cortisone and its effects fetched a group of scientists The Nobel Prize. Use of corticosteroid in select indications has been well documented in the literature. Hench et al and coworkers showed beneficial effects of cortisone in rheumatoid arthritis for which they received Nobel prize in $1950 .{ }^{16}$ Hollander et al proved that deleterious systemic side effects of steroids could be avoided by local injections. ${ }^{17}$ In the last 60 years there has been debate about beneficial and deleterious effects of local corticosteroids.

Tendo Achilles tendinosis is a spectrum of disorders ranging from paratenonitis where there is inflammation of peritendinous structure on one end and insertional tendinitis with rupture on the other end. ${ }^{18}$ Few Studies have shown short-term improvement following local steroid injections. ${ }^{6,7}$ Frequent relapses were seen in long-term. Intratendinous injection of steroid causes tendon degeneration at site of injection and has been associated with more incidence of ruptures. ${ }^{19}$ In a study done by Ferland et al for evaluating the effect of local corticosteroid injection in adult albino rabbit's Achilles tendon the following results were observed. Tendon necrosis seen in intratendinous injection group was an astonishing 100\% whereas in peritendinous injection group, tendon necrosis was a mere $5 \%{ }^{20}$

In a 10 year follow-up study done by Johanssen et al sonographic assessment of TA thickness was measured in 3 study groups 0cs-no steroid injection group, $1 \mathrm{cs}-1$ steroid injection group and $2 \mathrm{cs}-2$ steroid injection group. The groups receiving steroid injection showed statistically significant decrease in tendon size with a tendency to worsening. Also in the steroid group late ruptures were noted at 5-8 years post steroid injection. ${ }^{21}$ A meta-analysis done in 2010 by Coombes et al also showed poor outcomes with steroid injection. $^{22}$

In the present study $(\mathrm{N}=12)$, all of the patients $(100 \%)$ had previous complaints of retrocalcaneal pain lasting for months prior to rupture and $(\mathrm{N}=6) 50 \%$ of the patients had received intralesional steroid injections in the last one year prior to rupture. With all of the patients $(\mathrm{N}=12)$ presenting with insertional ruptures, tendon transfer was done for all patients. Peroneus Brevis was the tendon of choice in our institute because of its advantages like (a) no residual eversion weakness; (b) PB is an In-phase transfer (c) No weakness of great toe flexion associated with FHL. ${ }^{23}$

Raghunandan et al in 2014 in a study on neglected tendon ruptures $(\mathrm{n}=48)$ observed 29 patients had received intralesional steroid injection. ${ }^{24}$ Effect of pre operative steroid on outcome was not studied in this study. In their study author preferred FHL as the preferred choice for tendon augmentation and claimed higher post operative complications with Peroneus Brevis like wound infection (14.28\%), delayed wound healing $(28.57 \%)$ and superficial sensory problems. In our study done with Peroneus Brevis, complications like wound healing $(8 \%)$ and sensory problem $(8 \%)$ were seen. Both these complications were seen in Group A (steroid group). There were no complications in Group B.

In the present study, $100 \%$ good to excellent outcomes were seen both Group A and Group B, however the percentage of excellent outcome was better in Group B (Table 4). Where as in Raghunandan et al. good to excellent outcome was seen in $91 \%$ (44 of 48 ). There is no mention as to whether $9 \%$ fair to poor outcome was associated with prior steroid injections.

The present study there was an improvement in Mean AOFAS scores in both Group A (35.5 to 81) and Group B (41.16 to 90.16). The results in Group B was more in line with a study done by Wegrzyn $\mathrm{J}^{25}$ in 2010 where there was an improvement in AOFAS score from 64 to 98 at 79 months follow-up

In the present study, it was observed that there was improvement after surgery in both group A and B. However there was better improvement in Group B with no previous history of steroid injections as evidenced by both the scoring systems (Table 3 and 4). There was statistically significant improvement in Group B (No steroid) at 6 months postoperatively. The difference in outcomes in steroid group could be due to tendon degeneration, significant decrease in tensile strength and disruption of collagen bundles. In our study all the patients had insertional tendinitis and rupture. Microscopic Tendon degeneration at a more proximal area because of steroid injection could also have resulted in lower outcome.

\section{Limitations}

This was a single center study with smaller sample size. Hence projection of the results for a general population may not be accurate. A multicentre study with a larger sample and longer-term follow-up is needed for confirming the results obtained in the present study.

\section{Conclusion}

Better Functional outcome following augmentation surgeries is seen in patients with tendo Achilles rupture with no previous history of steroid injection than in patients with steroid-induced TA rupture. Uses of intralesional steroid correlates negatively with outcome.

\section{Conflict of Interest: None}

\section{References}

1. Maffulli N, Waterston SW, Squair J, Reaper J, Douglas AS. Changing incidence of Achilles tendon rupture in Scotland: a 15-year study. Clin J Sport Med. 1999;9:157160. [PMID: 10512344 DOI: 10.1097/00042752199907000-00007]

2. Saltzman L. C, Tearse D.S. Achilles Tendon Injuries. $J$ Am Acad Orthop Surg. 1998;6:316-325. 
3. Silbernagel KG, Thomeé R, Thomeé P. Eccentric overload training for patients with chronic Achilles tendon pain--a randomized controlled study with reliability testing of the evaluation methods. Scand J Med Sci Sports. 2001;11:197-206.

4. Maffulli N, Walley G, Sayana MK. Eccentric calf muscle training in athletic patients with Achilles tendinopathy. Disabil Rehabil. 2008;30:1677-1684.

5. Ohberg L, Alfredson H. Effects on neovascularisation behind the good results with eccentric training in chronic mid-portion Achilles tendinosis? Knee Surg Sports Traumatol Arthrosc. 2004;12:465-470.

6. Fredberg U, Bolvig L, Pfeiffer-Jensen M. Ultrasonography as a tool for diagnosis, guidance of local steroid injection and, together with pressure algometry, monitoring of the treatment of athletes with chronic jumper's knee and Achilles tendinitis: a randomized, double-blind, placebo-controlled study. Scand J Rheumatol. 2004;33:94-101.

7. Wetke E, Johannsen F, Langberg H. Achilles tendinopathy: a prospective study on the effect of active rehabilitation and steroid injections in a clinical setting. Scand J Med Sci Sports. 2015;25:e392-e399.

8. Newnham DM, Douglas JG, Legge JS, Friend JA. Achilles tendon rupture: an underrated complication of corticosteroid treatment. Thorax. 1991;46:853-854 [PMID: 1771608 DOI: 10.1136/ thx.46.11.853]

9. Josza J, Kannus P. Structure and metabolism of normal tendons. In: Human tendons. New York: Human Kinetics, 1997:46-95.

10. Unverfirth LJ, Olix ML. The effect of local steroid injections on tendon. J Bone Joint Surg (Am). 1973;55:1315.

11. Gottlieb NL, Riskin WG. Complications of local corticosteroid injections. JAMA. 1980;240:1547-8.

12. Kitaoka HB, Alexander iJ, Adelaar Rs. Clinical rating systems for the ankle-hindfoot, midfoot, hallux and lesser toes. Foot and Ankle int. 1994;15:349-353.

13. Ibrahim t, Beiri A, Azzabi M. Reliability and validity of the subjective component of the American orthopaedic Foot and Ankle society clinical rating scales. J Foot Ankle Surg. 2007;46:65-74.

14. Spennacchio P, Vascellari A. Outcome evaluation after Achilles tendon ruptures. A review of the literature. Joints. 2016 Jun 13;4(1):52-61.

15. Leppilahti J, Forsman K, Puranen J. outcome and prognostic factors of Achilles Rupture repair using a new scoring method. Clin orthop Relat Res. 1998:(346):152161.

16. Hench PS, Kendall FC. The effect of the adrenal cortex and of pituitary adrenocorticosterone hormone on RA: preliminary report. Proceedings of the Staff Meetings of the Mayo Clinic. 1949;24:181
17. Hollander JL, Brown EM, Jessar RA. Hydrocortisone and cortisone injected into arthritic joints. JAMA. 1951;147:1629-1635.

18. Paavola M, Paakkala T, Kannus P, Järvinen M: Ultrasonography in the differential diagnosis of Achilles tendon injuries and related disorders: A comparison between pre-operative ultrasonography and surgical findings. Acta Radiol. 1998;39:612-619.

19. Lee HB. Avulsion and rupture of the tendo calcaneus after injection of hydrocortisone. Br Med. 1 1957; ii: 395.

20. Ferland MA, Uhthoff HK. Necrose localis e due a uneinjection intratendineuse de gluco-corticoide: etude ex-perimentale comparative. Union Med Can. 1972; 101: 1768-1771.

21. Johannsen F, Jensen S, Wetke E. 10-year follow-up after standardised treatment for Achilles tendinopathy. BMJ Open Sport \& Exercise Medicine. 2018;0:e00415. doi:10.1136/ bmjsem-2018-000415

22. Coombes BK, Bisset L, Vicenzino B. Efficacy and safety of corticosteroid injections and other injections for management of tendinopathy: a systematic review of randomised controlled trials. Lancet. 2010;376:17511767.

23. Silver RL, de la Garza J, Rang M. The myth of muscle balance. A study of relative strengths and excursions of normal muscles about the foot and ankle. J Bone Joint Surg Br. 1985;67:432-437.

24. Raghunandan G. Management of Neglected Achilles tendon ruptures with Flexor Hallucis longus transfer. $J$ Foot Ankle Surg. (Asia-Pacific). 2014;1(1):5-8

25. Wegrzyn J, Luciani JF, Philippot R, Brunet-Guedj E, Moyen B, Besse JL Chronic Achilles tendon rupture reconstruction using a modified flexor hallucis longus transfer.

How to cite this article: Nagakiran K.V, Soraganvi P, Uma M.A, Sudeep P.M, Bharadwaj MSC. An analysis of functional outcome following tendon augmentation surgeries in patients presenting with steroid-induced tendo achilles rupture and spontaneous tendo achilles ruptures. Indian J Orthop Surg. 2018;4(4):394-401. 